Pesq. Vet. Bras. 31(5):398-406, maio 2011

\title{
Teores séricos e hepáticos de cobre, ferro, molibdênio e zinco em ovinos e caprinos no estado de Pernambuco'
}

\author{
Allan Vieira dos Santos Marques², Pierre Castro Soares ${ }^{2 *}$, Franklin Riet-Correa ${ }^{3}$, \\ lagmar Oliveira da Mota², Tércya Lucid de Araújo Silva², Álvaro Veloso Borba Neto², \\ Filipe Aureliano Pedrosa Soares ${ }^{2}$ e Sylvana Pontual de Alencar ${ }^{2}$
}

\begin{abstract}
Marques A.V.S., Soares P.C, Riet-Correa F., Mota I.O., Silva T.L.A., Borba Neto A.V., Soares F.A.P. \& Alencar S.P. 2011. [Serum and liver concentrations of copper, iron, zinc and molybdenum in sheep and goats in the state of Pernambuco.] Teores séricos e hepáticos de cobre, ferro, molibdênio e zinco em ovinos e caprinos no estado de Pernambuco. Pesquisa Veterinária Brasileira 31(5):398-406. Departamento de Medicina Veterinária, Universidade Federal Rural de Pernambuco, Rua Dom Manoel de Medeiros s/n, Recife, PE 52171-900, Brazil. E-mail: psoares@dmv.ufrpe.br

The aim of this research was to determine serum and liver concentrations of $\mathrm{Cu}, \mathrm{Mo}, \mathrm{Fe}$ and $\mathrm{Zn}$ in sheep and goats slaughtered in the semiarid region of the state of Pernambuco, northeastern Brazil, during the rainy and dry seasons, and to establish if $\mathrm{Cu}$ deficiency which occurs in the region is primary or secondary to high levels of Mo and/or Fe. Serum and liver samples from 141 goats and 141 sheep were submitted to wet digestion in nitric-perchloric acid and analyzed by coupled plasma atomic absorption spectrophotometry (ICPOES). The mean serum concentrations of Cu were $9.85 \pm 2.71 \mu \mathrm{mol} / \mathrm{L}$ in sheep and $11.37 \pm 2.57 \mu \mathrm{mol} / \mathrm{L}$ in goats. Mean Cu liver concentrations were $158.45 \pm 83.05 \mathrm{mg} / \mathrm{kg}$ in sheep and $152.46 \pm 79.58 \mathrm{mg} /$ $\mathrm{kg}$ in goats. Mean serum concentrations of Fe were $35.58 \pm 14.89 \mu \mathrm{mol} / \mathrm{L}$ in sheep and $25.06 \pm 8.10 \mu \mathrm{mol} / \mathrm{L}$ in goats. Mean liver concentrations of Fe were $156.10 \pm 55.99 \mathrm{mg} / \mathrm{kg}$ in sheep and $210.53 \pm 121.99 \mathrm{mg} / \mathrm{kg}$ in goats. Mean serum concentrations of Mo were $0.28 \pm 0.11 \mu \mathrm{mol} / \mathrm{L}$ in goats and $0.31 \pm 0.16 \mu \mathrm{mol} / \mathrm{L}$ in sheep. Mean liver concentrations of Mo were $6.53 \pm 4.13 \mathrm{mg} / \mathrm{kg}$ in goats and $8.10 \pm 4.01 \mathrm{mg} / \mathrm{kg}$ in sheep. Mean serum concentrations of $\mathrm{Zn}$ were $11.9 \pm 6.07 \mu \mathrm{mol} / \mathrm{L}$ in sheep and $11.79 \pm 7.42 \mu \mathrm{mol} / \mathrm{L}$ in goats. Mean liver concentrations of $\mathrm{Zn}$ were $126.43 \pm 51.50 \mathrm{mg} / \mathrm{kg}$ in sheep and $132.91 \pm 55.28 \mathrm{mg} / \mathrm{kg}$ in goats. Based on $\mathrm{Cu}$ serum and liver concentrations and on the sporadic occurrence of enzootic ataxia, $\mathrm{Cu}$ supplementation is recommended for grazing sheep and goats during the dry and the rainy seasons. Considering that serum and hepatic concentrations of Fe and Mo are within normal ranges or are marginal, it is suggested that the low Cu concentrations are not related with high Fe or Mo ingestion. Non significant differences were observed between serum and liver concentrations of $\mathrm{Cu}$ and $\mathrm{Mo}$, and between serum concentrations of $\mathrm{Fe}$ in samples collected during the rainy season and the dry season. Liver concentrations of Fe and serum and liver concentrations of $\mathrm{Zn}$ were significantly higher during the rainy season. Taking into account that serum and liver $\mathrm{Zn}$ concentrations in sheep and goats are considered marginal, supplementation with $\mathrm{Zn}$ is suggested for grazing sheep and goats, mainly during the dry season.
\end{abstract}

INDEX TERMS: Microelements, ruminants, blood, liver, copper deficiency, zinc deficiency, mineral deficiency.

\footnotetext{
${ }^{1}$ Recebido em 7 de julho de 2001.

Aceito para publicação em 8 de dezembro de 2010.

2 Departamento de Medicina Veterinária, Universidade Federal Rural de Pernambuco (UFRPE), Rua Dom Manoel de Medeiros s/n, Recife, PE 52171-900, Brasil. *Autor para correspondência: psoares@dmv.ufrpe.br

${ }^{3}$ Hospital Veterinário, Centro de Saúde e Tecnologia Rural, Universidade Federal de Campina Grande, Patos, PB 58700-000.
}

RESUMO.- $\mathrm{O}$ trabalho objetivou conhecer os teores de $\mathrm{Cu}$, Mo, Fe e Zn em soro e fígado de ovinos e caprinos criados na região semiárida do estado de Pernambuco e abatidos nas épocas da chuva e seca, e estabelecer se a carência de Cu é causada por deficiência primária de Cu ou secundária à ingestão de quantidades excessivas de $\mathrm{Fe}$ ou Mo. Amostras de soro e fígado de 141 ovinos e 141 caprinos 
foram submetidas à digestão úmida em ácido nítrico-perclórico e, posteriormente, analisados em espectrofotômetro de absorção atômica indutivamente acoplado (ICPOES). A concentração sérica de Cu em caprinos teve uma média de $9,85 \pm 2,71 \mu \mathrm{mol} / \mathrm{L}$ e em caprinos de $11,37 \pm 2,57 \mu \mathrm{mol} / \mathrm{L}$, enquanto que a concentração hepática média foi de $158,45 \pm 83,05 \mathrm{mg} / \mathrm{kg}$ para ovinos e $152,46 \pm 79,58 \mathrm{mg} / \mathrm{kg}$ pa-

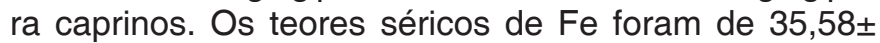
$14,89 \mu \mathrm{mol} / \mathrm{L}$ em ovinos e de $25,06 \pm 8,10 \mu \mathrm{mol} / \mathrm{L}$ em caprinos e as concentrações no fígado foram de $156,10 \pm 55,99 \mathrm{mg} /$ $\mathrm{kg}$ em ovinos e $210,53 \pm 121,99 \mathrm{mg} / \mathrm{kg}$ em caprinos. As con-

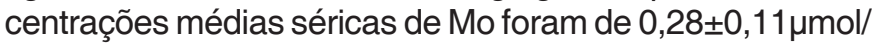
$\mathrm{L}$ em caprinos e $0,31 \pm 0,16 \mu \mathrm{mol} / \mathrm{L}$ em ovinos, enquanto que no fígado sua concentração foi de $6,53 \pm 4,13 \mathrm{mg} / \mathrm{kg}$ e $8,10 \pm 4,01 \mathrm{mg} / \mathrm{kg}$, respectivamente. A concentração sérica de $Z n$ foi de $11,9 \pm 6,07 \mu \mathrm{mol} / \mathrm{L}$ em ovinos e $11,79 \pm 7,42 \mu \mathrm{mol} /$ L em caprinos e a concentração no fígado foi de 126,43 $\pm 51,50 \mathrm{mg} / \mathrm{kg}$ e $132,91 \pm 55,28 \mathrm{mg} / \mathrm{kg}$ em ovinos e caprinos, respectivamente. Verificou-se variação na concentração destes minerais considerando os fatores de variação, como o período sazonal, espécie e sexo. Baseado nos valores observados, considerados marginais, e na ocorrência de surtos de ataxia enzoótica em caprinos e ovinos na região, recomenda-se a suplementação com Cu em animais a campo, tanto na seca quanto na chuva. Considerando as concentrações séricas e hepáticas de Fe e Mo, sugerese que as concentrações marginais de Cu não estejam diretamente relacionadas com o excesso destes minerais. Não foram encontradas diferenças significantes nas concentrações séricas e hepáticas de Cu e Mo e nas concentrações séricas de Fe entre as amostras coletadas na época da chuva a as coletadas na época seca. As concentrações hepáticas de Fe e as concentrações séricas e hepáticas de $\mathrm{Zn}$ foram significativamente maiores na época da chuva. Considerando que os teores de $\mathrm{Zn}$ sérico encontram-se abaixo dos valores considerados como marginais e os hepáticos dentro do limite de normalidade, embora próximos ao limite inferior da referência, recomenda-se a suplementação com Zn, principalmente durante o período da seca.

TERMOS DE INDEXAÇÃO: Microelementos, ruminantes, sangue, fígado, deficiência mineral, deficiência de cobre, deficiência de zinco.

\section{INTRODUÇÃO}

Junto com o fósforo, o cobre é um dos elementos mais carentes em ruminantes criados em todos os continentes. A carência de cobre em ruminantes pode ocorrer por menor aporte deste nutriente na dieta ou maior presença de outros elementos antagonizantes que diminuem a sua disponibilidade, tais como o Mo, S, Zn e Fe (Ortolani 2002, Riet-Correa 2004). Os dois primeiros microelementos citados podem interferir isoladamente ou em associação formando com o Cu fortíssima ligação metálica cujo complexo é insolúvel e indisponível. Estes mecanismos de ligação foram intensamente estudados nas últimas décadas por Underwood e Suttle (1999).
A hipocuprose é uma das deficiências de maior interesse em ruminantes, apresentando uma ampla variedade de sinais clínicos e extensa distribuição geográfica, tanto no Brasil quanto em outras partes do mundo (Marques et al. 2003). No Brasil há um bom conhecimento sobre as carências minerais em bovinos, assim como sobre as formas eficientes e econômicas de suplementação nesta espécie (McDowell 1999, Tokarnia et al. 2000, 2010). Porém, o conhecimento sobre carências minerais em ovinos e caprinos é limitado e pouco se sabe sobre as formas corretas de suplementação.

Muito recentemente, em estudo sobre doenças do sistema nervoso central em caprinos e ovinos no semiárido, Guedes et al. (2007) encontraram frequência de 3,17\% de casos de ataxia enzoótica, retratando a importância de melhor estudar esta doença nas condições do semiárido. Silva et al. (2004) e Riet-Correa (2007) citaram que é difícil estabelecer com precisão as exigências dos ruminantes com relação ao elemento cobre, em decorrência dos diversos fatores que atuam na disponibilidade desse mineral nos alimentos e na sua utilização pelos animais. Os ruminantes, em pastejo, frequentemente estão sujeitos a severas deficiências dietéticas de minerais, por isso o conhecimento da constituição mineral das pastagens naturais reveste-se de grande importância, especialmente em regiões de criação extensiva, nas quais o principal componente dietético dos animais são as pastagens naturais (Senger et al. 1997).

Objetivou-se, neste estudo, conhecer os teores de $\mathrm{Cu}$, $\mathrm{Fe}$, Mo e Zn em materiais biológicos de ovinos e caprinos, criados na região sertão do estado de Pernambuco, considerando os fatores sazonalidade, espécie e sexo, bem como averiguar se existe deficiência de Cu e se seu status está diretamente relacionado com a ação de elementos considerados antagonistas.

\section{MATERIAL E MÉTODOS}

\section{Plano amostral e característica das amostras}

As amostras de diferentes matrizes biológicas foram obtidas de animais encaminhados ao abatedouro da microrregião de Araripina situado na região sertão do estado de Pernambuco. Para relacionar os dados com a procedência dos animais, utilizou-se registro da divisão do Estado em regiões, conforme estabelecido pelo Instituto de Defesa Agropecuária do estado de Pernambuco. Foi realizado um inquérito, antes do abate dos animais, para caracterizar o sexo, estrato etário, escore nutricional e município. Tais informações foram úteis para caracterizar o critério de inclusão, considerando-se animais abatidos no Estado, em estabelecimentos sob o Serviço de Inspeção Federal (SIF) ou Serviço de Inspeção Sanitária Estadual (SISE) e animais procedentes dos municípios que compõem a região sertão. As amostras de fígado e soro dos animais foram obtidas considerando-se os municípios de Granito, Araripina e Ouricuri, na região sertão do estado de PE. Para tal região, foi efetivada amostragem de animais de ambos os sexos, espécies e por período sazonal, totalizando 141 amostras de ovinos e 141 de caprinos. 


\section{Período de coleta}

Amostras de sangue e fígado foram obtidas em dois períodos do ano (seco e chuvoso), sendo determinada coleta no terço final de cada um destes períodos, objetivando-se adequação do delineamento para caracterizar amostras obtidas no período de disponibilidade de nutrientes e no período de mobilização das reservas, pela escassez de alimentos. Para caracterizar os períodos de seca e chuva na região em questão, obtiveram-se registros de dados de temperaturas máximas e mínimas, umidade relativa do ar e precipitação pluviométrica junto ao Instituto Nacional de Meteorologia, definidos pela média dos últimos 20 anos. As coletas do período chuvoso foram realizadas nos meses de março e abril, por compreenderem o terço final da época de chuvas, já que em geral o período de chuva nesses municípios abrange os meses de dezembro a abril. As coletas do período seco foram realizadas nos meses de outubro e novembro, compreendendo o terço final da época de seca para os referidos municípios, pois em geral o período de seca nesses municípios abrange os meses de maio a dezembro. Nos abatedouros, os animais foram escolhidos ao acaso pelo Médico Veterinário do Serviço de Inspeção Sanitária do estabelecimento, conforme a procedência do animal.

\section{Colheita das amostras}

Sangue. Foram colhidas amostras de sangue, por venopunção jugular, em tubos para coleta à vácuo, sem anticoagulante para obtenção de soro. Tais amostras permaneceram em repouso, à temperatura ambiente, para a retração do coágulo. Posteriormente foram centrifugadas por período de 15 minutos a $500 \mathrm{G}$. As alíquotas de soro foram acondicionadas em tubos de polipropileno $(2 \mathrm{~mL})$ e armazenadas à temperatura de $-20^{\circ} \mathrm{C}$, para posterior procedimentos laboratoriais.

Tecido hepático. As amostras de fígado foram obtidas por meio de corte do órgão, em cerca de 50 gramas, com faca de aço inoxidável, quando foram colocadas sobre papel filtro, para retirada do excesso de sangue e alocadas em sacos plásticos, devidamente identificados e armazenados em freezer a $-20^{\circ} \mathrm{C}$.

\section{Determinação dos minerais}

Para a determinação em espectrometria de absorção atômica acoplado a massa dos elementos no soro, estes foram diluídos de 6,0 a 20,0 x com água Milli-Q, segundo Solaiman et al. (2001). Quanto às amostras de fígado, primeiramente procedeu-se com fragmentação com uso de lâmina de bisturi e alocadas dentro de vidro relógio (matéria úmida) para posterior secagem em estufa a $103^{\circ} \mathrm{C}$, por período de 24 horas, para obtenção da matéria seca. Após tal procedimento, todas as amostras foram pesadas em balança analítica. Todos os pesos foram registrados em protocolo individual e, por conseguinte, tais amostras foram colocadas em tubos de boro-silicato contendo ácido nítrico-perclórico $(4: 1 \mathrm{v} / \mathrm{v})$ e mantidas em repouso por 12 horas. Na seqüência, os tubos foram alocados em bloco digestor a temperatura de $150^{\circ} \mathrm{C}$. Ao término da digestão, foi adicionado volume de $10 \mathrm{~mL}$ de ácido clorídrico 0,1 $\mathrm{N}$, depositado em recipiente plástico, hermeticamente lacrado e encaminhado ao laboratório para procedimentos analíticos (Tebaldi et al. 2000).

Os elementos ( $\mathrm{Cu}, \mathrm{Mo}, \mathrm{Fe}$ e $\mathrm{Zn}$ ) foram determinados por espectrometria de absorção atômica acoplado a massa (ICPOES), utilizando-se aparelho modelo SpectrAA 200 G (Miles et al. 2001).

\section{Análise estatística}

As variáveis estudadas foram descritas por meio das médias e desvios-padrão. Os dados foram submetidos à análise de variância (Teste $F$ ) que separou como causa de variação o efeito de períodos sazonal, espécie e sexo. Nos casos em que houve significância no teste $F$ as médias dos tratamentos foram comparadas pelo Teste de Duncan. Os dados foram analisados por meio do programa computacional Statistical Analysis System Institute, SAS, (2000), utilizando-se o procedimento GLM (General Linear Model) do SAS. Para todas as análises estatísticas realizadas foi adotado o nível de significância $(P)$ de $5 \%$. O modelo utilizado foi o seguinte: $Y_{i j}=P+E$ $+S+P E S+E_{i j}$, onde: $Y_{i j}=$ valor observado; $P=$ efeito do período sazonal; $E$ = efeito da espécie; $S$ = efeito do sexo; $P E S$ $=$ Interação período sazonal $\mathrm{x}$ espécie $\mathrm{x}$ sexo; $\mathrm{E}_{\mathrm{ij}}=$ erro. $\mathrm{Em}$ sequência realizou-se nova análise de variância para avaliar as diferenças entre os fatores sexo e período sazonal por espécie (ovina e caprina) separadamente, segundo modelo: $Y_{\mathrm{i}}=$ $P+S+E_{i j}$, onde: $Y_{i j}=$ valor observado; $P=$ efeito do período sazonal; $S$ = efeito do sexo; $E_{i j}=$ erro.

\section{RESULTADOS}

No Quadro 1 encontram-se as médias gerais e desviospadrão da análise de variância dos elementos $\mathrm{Cu}, \mathrm{Fe}$, Mo e Zn no soro e fígado, nos fatores período, espécie e sexo, enquanto que no Quadro 2 estão os valores médios e desvios-padrão das concentrações séricas e hepáticas de $\mathrm{Cu}$, $\mathrm{Fe}$, Mo e Zn em ovinos e caprinos, em relação ao sexo e período sazonal, abatidos no semiárido de Pernambuco.

Considerando-se a análise estatística pela análise de variância para os fatores: espécie, sexo e período sazonal, verificou-se que a concentração sérica de Cu variou entre ovinos e caprinos $(P<0,0008)$ e que tanto a concentração sérica $(P<0,0001)$ quanto hepática $(P<0,0133)$ foram diferentes entre animais machos e fêmeas. Quanto ao Fe, verificou-se que houve diferença da concentração sérica $(P<0,0001)$ e hepática $(P<0,0033)$ deste elemento em relação aos ovinos e caprinos; além de que diferenças da concentração sérica de $\mathrm{Fe}$ foi encontrada entre machos e fêmeas $(P<0,0001)$ e hepática entre os períodos de seca e chuva $(P<0,0217)$. As concentrações séricas e hepáticas de Mo não foram diferentes quanto à espécie, sexo e período sazonal $(P>0,05)$. Já em relação ao $Z n$, tanto a concentração sérica $(P<0,0475)$ quanto hepática $(P<0,0280)$ foram diferentes entre os períodos de seca e chuva.

Menor concentração sérica de Cu foi observada nos animais da espécie ovina $(9,58 \pm 2,52 \mu \mathrm{mol} / \mathrm{L})$ em relação aos caprinos $(11,55 \pm 2,68 \mu \mathrm{mol} / \mathrm{L})$. Quanto ao sexo, menor concentração foi observada nos machos $(9,58 \pm 2,52 \mu \mathrm{mol} /$ L) do que nas fêmeas $(11,55 \pm 2,68 \mu \mathrm{mol} / \mathrm{L})$. Já em relação à concentração hepática de $\mathrm{Cu}$, menor concentração foi observada nos machos, de $135,56 \pm 96,19 \mathrm{mg}$ por $\mathrm{kg}$ de matéria seca $(\mathrm{mg} / \mathrm{kg} \mathrm{MS})$ do que nas fêmeas $(186,14 \pm 98,10 \mathrm{mg} / \mathrm{kg})$ (Quadro 1).

Menor concentração sérica de Fe foi observada nos caprinos $(25,06 \pm 8,10 \mu \mathrm{mol} / \mathrm{L})$ do que nos ovinos $(35,58 \pm$ $14,89 \mu \mathrm{mol} / \mathrm{L})$ e menor concentração nas fêmeas $(27,02 \pm$ $9,61 \mu \mathrm{mol} / \mathrm{L})$ com relação aos machos $(35,25 \pm 15,29 \mu \mathrm{mol} /$ 
Quadro 1. Médias gerais e desvios-padrão da análise de variância dos elementos $\mathrm{Cu}, \mathrm{Fe}$, Mo e Zn no soro e fígado, nos fatores período, espécie e sexo, de animais abatidos no semiárido de Pernambuco

\begin{tabular}{|c|c|c|c|c|c|c|}
\hline \multirow[t]{3}{*}{ Variáveis } & \multicolumn{6}{|c|}{ Fatores } \\
\hline & \multicolumn{2}{|c|}{ Período } & \multicolumn{2}{|c|}{ Espécie } & \multicolumn{2}{|c|}{ Sexo } \\
\hline & Seca & Chuva & Ovino & Caprino & Macho & Fêmea \\
\hline \multicolumn{7}{|c|}{ Soro $(\mu \mathrm{mol} / \mathrm{L})$} \\
\hline $\mathrm{Cu}$ & $10,15 \pm 2,64^{A^{*}}$ & $10,57 \pm 2,85^{A}$ & $9,85 \pm 2,71^{B}$ & $11,37 \pm 2,57^{A}$ & $9,58 \pm 2,52^{\mathrm{B}}$ & $11,55 \pm 2,68^{A}$ \\
\hline $\mathrm{Fe}$ & $32,77 \pm 14,23^{A}$ & $31,20 \pm 13,58^{A}$ & $35,58 \pm 14,89^{A}$ & $25,06 \pm 8,10^{B}$ & $35,25 \pm 15,29^{A}$ & $27,02 \pm 9,61^{\mathrm{B}}$ \\
\hline Mo & $0,32 \pm 0,16^{A}$ & $0,28 \pm 0,14^{A}$ & $0,31 \pm 0,16^{A}$ & $0,28 \pm 0,11^{A}$ & $0,31 \pm 0,17^{\mathrm{A}}$ & $0,29 \pm 0,12^{A}$ \\
\hline $\mathrm{Zn}$ & $10,62 \pm 6,34^{B}$ & $12,85 \pm 6,57^{\mathrm{A}}$ & $11,90 \pm 6,07^{A}$ & $11,79 \pm 7,42^{\mathrm{A}}$ & $11,58 \pm 7,10^{A}$ & $12,26 \pm 5,68^{A}$ \\
\hline \multicolumn{7}{|c|}{ Fígado $\left(\mathrm{mg} / \mathrm{kg}^{\star \star}\right)$} \\
\hline & Seca & Chuva & Ovino & Caprino & Macho & Fêmea \\
\hline $\mathrm{Cu}$ & $172,10 \pm 94,85^{A}$ & $143,69 \pm 99,42^{A}$ & $158,45 \pm 83,05^{A}$ & $152,46 \pm 79,58^{A}$ & $135,56 \pm 96,19^{B}$ & $186,14 \pm 98,10^{A}$ \\
\hline $\mathrm{Fe}$ & $169,23 \pm 109,89^{B}$ & $210,00 \pm 101,52^{\mathrm{A}}$ & $210,53 \pm 121,99^{A}$ & $156,10 \pm 55,99^{B}$ & $198,13 \pm 72,96^{A}$ & $182,27 \pm 78,48^{A}$ \\
\hline Mo & $7,37 \pm 4,18^{\mathrm{A}}$ & $7,69 \pm 4,10^{\mathrm{A}}$ & $8,10 \pm 4,01^{\mathrm{A}}$ & $6,53 \pm 4,13^{\mathrm{A}}$ & $7,71 \pm 4,02^{\mathrm{A}}$ & $7,31 \pm 4,09^{A}$ \\
\hline $\mathrm{Zn}$ & $117,81 \pm 52,58^{B}$ & $137,46 \pm 51,52^{\mathrm{A}}$ & $126,43 \pm 51,50^{A}$ & $132,91 \pm 55,28^{A}$ & $128,05 \pm 53,31^{A}$ & $129,57 \pm 52,36^{A}$ \\
\hline
\end{tabular}

Letras maiúsculas distintas na mesma linha, dentro de cada fator (período sazonal, espécie e sexo), diferem ao nível de 5\% de probabilidade. ${ }^{* *} \mathrm{mg} / \mathrm{kg}=\mathrm{mg}$ por $\mathrm{kg}$ de matéria seca.

Quadro 2. Valores médios e desvios-padrão das concentrações séricas e hepáticas de $\mathrm{Cu}$, Fe, Mo e Zn em ovinos e caprinos, em relação ao sexo e período sazonal, abatidos no semiárido de Pernambuco

\begin{tabular}{|c|c|c|c|c|c|c|c|c|c|}
\hline \multirow{2}{*}{\multicolumn{2}{|c|}{$\begin{array}{c}\text { Material biológico/ } \\
\text { Minerais }\end{array}$}} & \multicolumn{4}{|c|}{ Espécies/Sexo } & \multicolumn{4}{|c|}{ Espécies/Período sazonal } \\
\hline & & \multicolumn{2}{|c|}{ Ovinos } & \multicolumn{2}{|c|}{ Caprinos } & \multicolumn{2}{|c|}{ Ovinos } & \multicolumn{2}{|c|}{ Caprinos } \\
\hline Soro & $\begin{array}{c}\mathrm{Cu} \\
(\mu \mathrm{mol} / \mathrm{L})\end{array}$ & $10,92 \pm 2,56^{A}$ & $9,42 \pm 2,67^{B}$ & $12,10 \pm 2,70^{\mathrm{A}}$ & $10,14 \pm 1,80^{B}$ & $9,22 \pm 2,34$ & $10,3 \pm 2,89$ & $11,74 \pm 2,36$ & $11,05 \pm 2,74$ \\
\hline Fígado & $\begin{array}{c}\mathrm{Cu} \\
(\mathrm{mg} / \mathrm{kg})\end{array}$ & $218,61 \pm 93,49^{A}$ & $133,45 \pm 92,37^{\mathrm{B}}$ & $157,87 \pm 78,78$ & $143,15 \pm 82,36$ & $185,10 \pm 88,28$ & $137,95 \pm 87,04$ & $155,20 \pm 93,40$ & $149,37 \pm 62,33$ \\
\hline Soro & $\begin{array}{c}\mathrm{Fe} \\
(\mu \mathrm{mol} / \mathrm{L})\end{array}$ & $29,92 \pm 11,06^{B}$ & $37,85 \pm 15,68^{A}$ & $24,59 \pm 7,56$ & $25,86 \pm 9,12$ & $36,99 \pm 15,00$ & $34,52 \pm 14,86$ & $25,61 \pm 9,35$ & $24,57 \pm 6,96$ \\
\hline Soro & $\begin{array}{c}\mathrm{Mo} \\
(\mu \mathrm{mol} / \mathrm{L})\end{array}$ & $0,32 \pm 0,16$ & $0,31 \pm 0,17$ & $0,28 \pm 0,08$ & $0,28 \pm 0,14$ & $0,33 \pm 0,18$ & $0,30 \pm 0,15$ & $0,31 \pm 0,12$ & $0,26 \pm 0,10$ \\
\hline Fígado & $\begin{array}{c}\text { Mo } \\
(\mathrm{mg} / \mathrm{kg})\end{array}$ & $7,44 \pm 4,17$ & $8,36 \pm 3,94$ & $7,21 \pm 4,07$ & $5,35 \pm 4,06$ & $8,27 \pm 3,97$ & $7,96 \pm 4,07$ & $7,17 \pm 4,09$ & $5,80 \pm 4,14$ \\
\hline Soro & $\begin{array}{c}\mathrm{Zn} \\
(\mu \mathrm{mol} / \mathrm{L})\end{array}$ & $13,92 \pm 6,74$ & $11,38 \pm 5,74$ & $11,49 \pm 4,58$ & $12,30 \pm 10,86$ & $9,79 \pm 3,02^{B}$ & $13,48 \pm 7,22^{A}$ & $12,01 \pm 9,61$ & $11,60 \pm 4,93$ \\
\hline
\end{tabular}

* Letras maiúsculas distintas na mesma linha, dentro de cada fator (sexo e período sazonal), diferem ao nível de $5 \%$ de probabilidade.

L). Quanto ao Fe hepático, menor concentração foi observada nos animais da espécie caprina $(156,10 \pm 55,99 \mathrm{mg} / \mathrm{kg})$ do que os da espécie ovina $(210,53 \pm 121,99 \mathrm{mg} / \mathrm{kg})$ e menor concentração hepática foi registrada no período de seca $(169,23 \pm 109,89 \mathrm{mg} / \mathrm{kg})$ do que no período de chuva $(210,00 \pm 101,52 \mathrm{mg} / \mathrm{kg})$ (Quadro 1).

Menor concentração sérica de Zn foi observada no período de seca $(10,62 \pm 6,34 \mu \mathrm{mol} / \mathrm{L})$ em relação ao período de chuva $(12,85 \pm 6,57 \mu \mathrm{mol} / \mathrm{L})$ e menor concentração hepática de $\mathrm{Zn}$ foi observada no período de seca $(117,81 \pm 5258 \mathrm{mg} / \mathrm{kg})$ do quando comparado com o período de chuva $(137,46 \pm 51,52 \mathrm{mg} / \mathrm{kg}$ ) (Quadro 1).

Com base na análise estatística acima descrita, foi realizada nova análise de variância para estudar os fatores: sexo e período sazonal, separadamente por espécie (ovina e caprina), tanto no soro quanto no fígado. Assim sendo, em ovinos, maior média do Cu sérico foi registrado nas fêmeas em relação aos machos $(p<0,0153)$, e maior mé- dia do Fe sérico nos machos do que nas fêmeas $(p<0,0212)$. Quanto à concentração hepática do Cu na espécie ovina, também foi observada maior concentração de Cu nas fêmeas em relação aos machos $(p<0,0136)$. Já em relação aos caprinos, também maior concentração sérica de $\mathrm{Cu}$ foi registrada nas fêmeas em relação aos machos $(p<0,0096)$. No fator período sazonal, verificou-se maior média do Zn sérico $(p<0,0034)$, Zn hepático $(p<0,0034)$ e Fe hepático $(p<0,0458)$ no período de chuva do que no período de seca (Quadro 2).

\section{DISCUSSÃO}

A concentração sérica de Cu em caprinos teve uma média de $9,85 \mu \mathrm{mol} / \mathrm{L}$ e em caprinos de $11,37 \mu \mathrm{mol} / \mathrm{L}$. Verifica-se que tal concentração sérica foi, em geral, menor que os encontrados por Oregui \& Bravo (1993), cujo intervalo va-

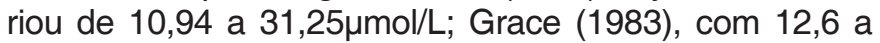
$18,9 \mu \mathrm{mol} / \mathrm{L}$; Santos et al. (2006), com média de 
12,9 $\pm 1,3 \mu \mathrm{mol} / \mathrm{L} ;$ Pott et al. (1999), com média de 10,16 $\mu \mathrm{mol} /$ L; e Solaiman et al. (2001), com média de 18,11 $\pm 0,63 \mu \mathrm{mol} /$ L. Conforme descrito por Underwood \& Suttle (1999), valores séricos de 3 a $9 \mu \mathrm{mol} / \mathrm{L}$ são considerados como valores marginais para situação de deficiência inaparente de $\mathrm{Cu}$, tanto para caprinos quanto para ovinos.

Já em relação à concentração hepática (Quadros 1 e 2), verificou-se uma amplitude, também independente dos fatores, de 135,56 a 186,14mg/kg MS, com média geral de $158,45 \mathrm{mg} / \mathrm{kg}$ para ovinos e $152,46 \mathrm{mg} / \mathrm{kg}$ para caprinos. Oregui \& Bravo (1993) descrevem que valor médio de Cu hepático em torno de $500 \mathrm{mg} / \mathrm{kg}$ da $\mathrm{MS}$, e que em condições de aporte baixo ou alto, pode-se alcançar concentrações hepáticas inferiores a $30 \mathrm{mg} / \mathrm{kg}$ e superiores a 750 $1.000 \mathrm{mg} / \mathrm{kg}$, respectivamente. Blood (1994) refere concentração hepática de Cu igual ou superior a $200 \mathrm{mg} / \mathrm{kg}$ como normal para ovinos. Já Grace (1983), faz referência a valores de 150 a $1.200 \mathrm{mg} / \mathrm{kg}$ de Cu hepático como normal. Outros estudos mostram concentração hepática de Cu com

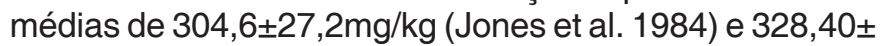
$30,84 \mathrm{mg} / \mathrm{kg}$ (Antonelli 2007).

Santos et al. (2006) reportaram aspectos clínicos da ataxia enzoótica em ovinos e caprinos criados no município de Surubim, Pernambuco, e encontraram valores médios de Cu hepático, nos animais com sintomatologia desta enfermidade, de 19,4 a $140 \mathrm{mg} / \mathrm{kg}$. Outro estudo a cerca da deficiência de $\mathrm{Cu}$ e Co em bovinos e ovinos, em diferentes regiões do Brasil, identificou valores médios da concentração hepática de Cu em ovinos de $125,43 \pm 86,57 \mathrm{mg} / \mathrm{kg}$ da MS (Tokarnia et al. 1971). Considerando os dados observados, os animais encontravam-se numa faixa considerada de risco para deficiência. De acordo com Bondan et al. (1991) as concentrações hepáticas de Cu constituem índices sensíveis a baixos aportes do elemento e fornecem valioso auxílio no diagnóstico de hipocrupose. Já Suttle (1974) descreve que a concentração do Cu hepático seja mais um critério relacionado às reservas existentes do que um indicador de deficiência. De todo modo, deve-se recorrer à análise de $\mathrm{Cu}$, bem como de outros elementos essenciais, em diferentes materiais biológicos, para se ter uma compreensão mais precisa das reservas de estoque e perfil homeostático destes elementos no organismo.

Verifica-se, por tanto, que tais animais se encontram em situação de deficiência inaparente. Esses resultados e a ocorrência de ataxia enzoótica na região semiárida (Santos et al. 2006, Guedes et al. 2007) sugerem a necessidade de suplementação com cobre em caprinos e ovinos a pastejo. Peixoto et al. (2005) reportam que as necessidades de suplementação variam com a área geográfica, época do ano e manejo alimentar do rebanho, além de que adequação protéico-energética da dieta com adequada disponibilidade de volumoso. Segundo estes mesmos autores, animais recebendo dietas com quantidades insuficientes de minerais ou rações desequilibradas que resultam em carência de um ou mais elementos, há que se corrigir para que os mesmos possam expressar o potencial genético para aspectos produtivos e saúde animal. Embora se identifique que existe uma variação dos intervalos da concentração sérica e hepática de Cu nos ruminantes por diferentes autores, há de considerar que atenção especial seja devida no sentido de identificar deficiência inaparente nos animais e fazer uso de medidas de controle com a adequada suplementação tanto mineral quanto energética e protéica, evitando-se, assim, prejuízos econômicos com enfermidades relacionadas com a deficiência do $\mathrm{Cu}$, bem como morte de animais.

Em relação à variável sexo, foi encontrada diferença significativa $(p<0,05)$ em que as fêmeas tiveram teores aumentados de $\mathrm{Cu}$ em relação aos machos, tanto no soro quanto no fígado, porém não se encontrou inferência na literatura que justifique ou explique estes resultados. Sugerese, hipoteticamente, que deva haver relação com perfil hormonal, em que estes tenham ação sobre a capacidade de metabolização deste micro-elemento. Ortolani (2002) descreve que fêmeas parecem ser mais predispostas ao desenvolvimento do quadro de intoxicação cúprica cumulativa e que esteja relacionado com ação do estradiol, o qual aumenta a retenção de Cu no fígado; já o estradiol favorece a síntese de metalotioneína interferindo na absorção do $\mathrm{Cu}$ ao nível intestinal. Geralmente os trabalhos descrevem os mecanismos de regulação e absorção do Cu com base nas características animais (espécie, raça e idade), natureza da fonte de Cu e características da dieta, porém não se encontram trabalhos que discutam o fator sexual como fonte de variação no metabolismo do Cu em pequenos ruminantes. Segundo Underwood \& Suttle (1999), a natureza das alterações clínicas e patológicas em relação ao Cu e outros elementos como o $\mathrm{Fe}, \mathrm{Zn}$ e Mo variam amplamente, tendo como fatores de variação a espécie, raça, idade sexo, grau e tempo de duração da deficiência e toxidez.

Santos et al. (2006) verificaram que a incidência de ataxia enzoótica em caprinos foi maior que em ovinos, embora não encontraram na literatura trabalhos que descrevessem o porque da diferença de susceptibilidade entre espécies. Owen (1965) descreve que os teores de $\mathrm{Cu}$, tanto sérico quanto hepático, são menores em ovinos, indicando que o limiar para ocorrência da enfermidade é mais baixa nesta espécie. Segundo Riet-Correa (2004) os caprinos são a espécie com maiores necessidades de Cu e menos susceptível à intoxicação do que os ovinos. Deste modo, há necessidade de estudos para averiguar melhor tal condição.

Uma importante consideração feita por Antonelli (2007), é que nos capins, principalmente no período seco, grande parte do Cu se apresenta como Cu metálico, o qual é pouco absorvido pelo organismo para atender as necessidades orgânicas; quando da fenação ou ensilagem dos capins, o Cu se complexa com proteínas, elevando-se sua disponibilidade. Por tal motivo, justifica-se que no período seco tenha-se encontrado teores marginais do Cu e também de seus antagonistas.

Conforme dados de Underwood \& Suttle (1999) e Blood (1994), a concentração sérica de Fe considerada normal para pequenos ruminantes é de $34,6 \pm 1,25 \mu \mathrm{mol} / \mathrm{L}$ a $37,45 \mu \mathrm{mol} / \mathrm{L}$, enquanto que no fígado este elemento tem 
uma variação de 181 a 380 mg/kg (Tokarnia et al. 1988). Já Jones et al. (1984) fazem referência de valor médio de $138,8 \pm 17,8 \mathrm{mg} / \mathrm{kg}$. Neste estudo pode-se verificar que o teor sérico de $\mathrm{Fe}$ foi de $35,58 \mu \mathrm{mol} / \mathrm{L}$ em ovinos e de $25,06 \mu \mathrm{mol} /$ $\mathrm{L}$ em caprinos e no fígado foi de $156,10 \mathrm{mg} / \mathrm{kg}$ em ovinos e $210,53 \mathrm{mg} / \mathrm{kg}$ em caprinos. Segundo esses autores, valores inferiores a $29 \mu \mathrm{mol} / \mathrm{L}$ de Fe no soro são considerados marginais como fator de risco para situação de deficiência, o que chama atenção para os valores médios de $25,06 \mu \mathrm{mol} /$ L, em caprinos na estação seca, e de $24,59 \mu \mathrm{mol} / \mathrm{L}$, em fêmeas desta espécie, encontrados neste estudo no semiárido de Pernambuco. Já valores superiores a $39 \mu \mathrm{mol} / \mathrm{L}$ de Fe no soro são excessivos (Jones et al. 1984), porem em nenhum dos fatores estudados foram registrados teores indicativos de excesso sérico deste microelemento.

Analisando os fatores expressos nos Quadros 1 e 2 é possível verificar que as concentrações de Fe tanto séricas quanto hepáticas foram menores para os caprinos em relação aos ovinos e que na época de seca a concentração hepática foi menor quando comparado com o período de chuva. Esta última observação é compatível com a condição sazonal na região estudada, onde se verifica que nos meses de maio a dezembro, registrou-se menor distribuição de chuvas, comprometendo a formação de pastagens, associado a pouca ou nenhuma suplementação alimentar nesse período.

Santos et al. (2006), registraram casos de ataxia enzoótica em ovinos no município de Surubim, Pernambuco, e consideram que no período de seca as pastagens tornamse escassas fazendo com que os animais pastem mais rente ao solo. Verificaram que este era arenoso e comumente recobria, em forma de poeira, as forragens disponíveis para os animais. Deste modo os animais ingeriam uma maior quantidade de solo, o qual continha teores médios relativamente altos de $\mathrm{Fe}(8600 \mathrm{mg} / \mathrm{kg})$. Como não foi feito análise de solo e forragens, não é possível relacionar os teores sanguíneos e hepáticos com os disponíveis nestes dois materiais. Seguramente estudos devem ser feitos para averiguar as características do solo nos municípios estudados.

Embora esteja bem estabelecido que mudanças na ingestão de Fe possam influenciar o metabolismo do Cu em animais, pouca importância tem sido atribuída ao Fe como causa de deficiência de $\mathrm{Cu}$ em ruminantes sob condições de criação extensiva (Humphries 1983). Baseando-se na literatura (Tokarnia et al. 1999, Underwood \& Suttle 1999) e dados do presente estudo, é importante estudar o perfil orgânico de Cu não isoladamente, mas, sim, em conjunto com outros elementos considerados antagonistas, verificandose se a condição de deficiência é primária ou secundária.

Com base nos dados aqui observados, fica evidente que as concentrações encontradas de Cu em limites marginais não estejam diretamente relacionadas com o excesso de Fe, como visto por Underwood \& Suttle (1999) e Santos et al. (2006); estando tal condição mais relacionada com a qualidade das forragens e falha na alimentação com nutrientes capazes de biodisponibilizar o Cu em ní- veis adequados para atender a demanda de várias rotas metabólicas e promover bom desempenho aos animais. A teoria de ingestão de altos teores de Fe em época de escassez de alimentos, sendo este de origem do solo rico neste elemento (Santos et al. 2006), necessita de maiores estudos, visto que os municípios de Araripina, Granito e Ouricuri também estão localizados na região sertão do estado de Pernambuco, e que estudos devem ser conduzidos para verificar a variabilidade de fatores responsáveis por diferentes perfis tanto de estoque quando homeostático e funcional do Cu e seus antagonistas.

Outro aspecto a ser considerado na maior concentração tanto sérica quanto hepática de Fe nos animais da espécie ovina é que tal fato possa ter relação com o habito alimentar destes animais, uma vez que os ovinos tendem a pastar mais rente ao solo preferindo vegetais de baixo porte ao contrário dos caprinos. De acordo com o postulado por Santos et al. (2006), poderia haver ingestão de gramíneas com solo, apresentando elevados teores de Fe. Trabalhos realizados no semiárido nordestino (Leite et al. 1995, Araújo FiIho et al. 1996) demonstraram uma maior preferência de ovinos por gramíneas, quando comparados com caprinos, tanto no período chuvoso quanto no período seco. Por outro lado, os caprinos demonstraram uma maior preferência por dicotiledôneas herbáceas e brotos de folhas de árvores e arbustos em ambos os períodos, o que poderia influir nos teores minerais presentes nos tecidos.

Segundo Borges et al. (2005), a deficiência marginal de $\mathrm{Cu}$, por ser a mais comum, acarreta mais prejuízos do que a deficiência severa. Taxas inadequadas de Cu na dieta podem causar diminuição do crescimento e queda dos índices reprodutivos, sem apresentar sinais clínicos característicos.

As concentrações médias séricas de Mo foram de $0,28 \mu \mathrm{mol} / \mathrm{L}$ em caprinos e $0,31 \mu \mathrm{mol} / \mathrm{L}$ em ovinos, enquanto que no fígado sua concentração variou de 6,53 e $8,10 \mathrm{mg} /$ $\mathrm{kg}$, respectivamente. Quanto aos valores séricos, estes são inferiores aos encontrados por diferentes autores. Van Ryssen \& Stielau (1981) encontraram valores de 0,63 $\pm 0,21 \mu \mathrm{mol} / \mathrm{L}$, quando avaliaram o efeito de diferentes níveis de Mo dietético no metabolismo do $\mathrm{Cu}$ e Mo em ovinos alimentados com elevados teores de Cu e S. Botha et al (1995), encontraram 0,52 $\pm 0,42 \mu \mathrm{mol} / \mathrm{L}$, estudando a farmacocinética do tetratiomolibdato em ovinos e Antonelli (2007), encontrou teores séricos de $0,8 \pm 0,19 \mu \mathrm{mol} / \mathrm{L}$, quando estudou o efeito do uso de sal mineral rico em Mo na intoxicação cúprica cumulativa. Apenas Pott et al. (1999), avaliando o efeito de dietas com elevado teor de Mo no metabolismo do Mo e Cu em ovinos, encontraram valor médio de Mo hepático $(0,10 \mu \mathrm{mol} / \mathrm{L})$ inferior aos encontrados neste estudo.

Já em relação aos teores hepáticos e considerando os dados de grupos controle de diferentes delineamentos experimentais, foi possível encontrar uma amplitude de valores, que variaram de $1,80 \mathrm{mg} / \mathrm{kg}$ (Allen \& Gawthorne 1987, $2,9 \mathrm{mg} / \mathrm{kg}$ (Van Ryssen \& Stielau 1981), 3,62 mg/kg (Antonelli 2007), 3,80mg/kg (Jones et al 1984), 5,88mg/kg 
(Pott et al 1999) e 8,55mg/kg (Gonzáles et al. 2000). Tais valores médios da concentração hepática de Mo estão abaixo dos encontrados nos animais deste estudo, porém próximos aos encontrados por Pott et al. (1999) e Van Ryssen \& Stielau (1980). Estes últimos autores estudaram oferta de dietas com altos teores de Cu e Mo e três crescentes teores de $\mathrm{S}$, encontrando valores de Mo que variaram de 6,4 a $10,7 \pm 1,39 \mathrm{mg} / \mathrm{kg}$. Verificaram, ainda, relação linear positiva do aumento de S na dieta e menor concentração hepática de Mo.

Considerando a ampla variação de valores de referência de Mo em soro e fígado, poucos trabalhos estão disponíveis, em relação à espécie caprina e a animais criados na região Nordeste do Brasil. Muito facilmente são encontrados trabalhos que reportam valores de Mo em componentes dietéticos e solo, relacionando-se com o metabolismo de $\mathrm{Cu}$, Mo e S. Diante de tal limitação, tornando-se necessários estudos para caracterizar melhor o perfil deste elemento em diferentes materiais biológicos.

O metabolismo do Mo é complexo e seu requerimento para ruminantes é extremamente baixo, sendo fortemente influenciado por sua concentração nos alimentos, bem como pela concentração de $S$, o qual interfere na sua absorção, retenção e excreção (Grace 1983, Underwood \& Suttle 1999), daí ser possível justificar a ampla variação encontrada neste estudo. Segundo Tokarnia et al. (1999), no Brasil, as concentrações de Mo em fígado de animais e também em pastagens estão dentro dos valores considerados adequados.

Segundo Allen e Gawthorne (1987), quando a dieta é enriquecida com Mo e $S$, moléculas de tiomolibdatos são formados, tornando o $\mathrm{Cu}$ indisponível, permitindo, assim, situações de baixa concentração tanto hepática quanto sérica do Cu. Com base nos resultados, é possível verificar que de acordo com análise da reserva homeostática, o Mo apresentou-se abaixo dos limites considerados normais em diferentes investigações, havendo necessidade de caracterizar valores de referência para tais espécies, no que diz respeito aos valores normais, marginais e deficientes, nas reservas tanto homeostáticas quanto de estoque, para poder estabelecer diagnóstico mais confiável do perfil deste microelemento em animais de interesse pecuário.

Neste estudo, a concentração sérica de $\mathrm{Zn}$ foi de $11,9 \mu \mathrm{mol} / \mathrm{L}$ em ovinos e $11,79 \mu \mathrm{mol} / \mathrm{L}$ em caprinos e a concentração no fígado foi de $126,43 \mathrm{mg} / \mathrm{kg}$ e $132,91 \mathrm{mg} / \mathrm{kg}$ em ovinos e caprinos, respectivamente. Os teores séricos de $\mathrm{Zn}$ considerados como normais para pequenos ruminantes variam de $12 \mathrm{a} 18 \mu \mathrm{mol} / \mathrm{L}$ (Sanz Lorenzo et al. 1996) e 12,3 a $18,5 \mu \mathrm{mol} / \mathrm{L}$ (Underwood \& Suttle 1999). Segundo Sanz Lorenzo et al. (1996), valor médio de 11,0 $4 \mathrm{~mol} / \mathrm{L}$ é considerado como limite marginal para casos de deficiência. Já em relação aos teores hepáticos, Tokarnia et al. (1988) reportam que teores normais de Zn no fígado estão em torno de 101 a $200 \mathrm{mg} / \mathrm{kg}$, enquanto que Antonelli (2007) faz referência a valores de 120 a 138mg/kg.Verifica-se, portanto que os teores de $\mathrm{Zn}$ sérico encontram-se abaixo dos valores considerados como marginais e os hepáticos dentro do limite de normalidade, embora próximos ao limite inferior da referência.

Importante considerar que menores concentrações tanto séricas quanto hepáticas foram registradas no período de seca e tal fato reveste de relevância e tem provável relação com a qualidade das forragens oferecidas aos animais nesse período. Além disso, a região compreendida neste estudo caracteriza-se por apresentar um cenário pluviométrico característico de deficiência hídrica anual (entre 800 e $1000 \mathrm{~mm}$ ) e índice de aridez que chega até $70 \%$, denotando um período de deficiência alimentar, com significativa redução na oferta de diferentes nutrientes, tais como esses micro-elementos essenciais para a saúde dos caprinos e ovinos.

Moraes et al. (1998) avaliaram amostras de fígado de várias regiões do Brasil e encontraram valores de $Z n$ abaixo dos considerados normais. Particularmente no estado do Piauí e região litorânea do Ceará (Municípios de Aracati e Pacatuba), mais da metade das amostras apresentaram teores baixos dos considerados normais, indicando a ocorrência de deficiência inaparente de Zn. A absorção do Zn pode ainda ser afetada pela interação exercida por outros elementos como $\mathrm{Ca}$, Cu e Fe. Porém, conforme foi constatado, as concentrações tanto do Cu quanto do Fe não foram tão elevadas a ponto de relacionar a ação antagonista ou sinérgica entre estes elementos. Em trabalho recente, Antonelli (2007) constatou que quanto mais alto os teores de Zn hepático mais alto eram os teores de Cu hepático.

Um dos aspectos mais relevantes em relação ao $\mathrm{Zn}$ é que sua deficiência pode causar falha de expressão gênica e redução do apetite. Animais que têm redução do apetite têm sérios comprometimentos em parâmetros produtivos, assim como menor capacidade reprodutiva (Underwood \& Suttle 1999). Os teores de $\mathrm{Zn}$ encontrados neste trabalho, próximos ou abaixo dos limites normais, sugerem que animais criados nesses municípios podem apresentar falhas reprodutivas e redução de apetite. Portanto é recomendada a suplementação com este mineral, principalmente na estação seca. Contudo, estudos devem ser conduzidos no sentido de comprovar à carência de $\mathrm{Zn}$ e determinar formas de suplementação seletiva.

Apesar dos valores marginais de $\mathrm{Cu}$ e $\mathrm{Zn}$ encontrados em caprinos e ovinos abatidos no sertão de Pernambuco é importante ressaltar que os valores em animais que permanecem nas pastagens podem ser ainda menores, já que animais deficientes tendem a ter seu crescimento corporal prejudicado, não atingindo o peso requerido para abate (Bondan et al. 1991). Segundo McDowell (1999), análises de tecidos ou fluidos animais, além das concentrações de certas enzimas, metabólitos ou compostos orgânicos com os quais determinados minerais estão funcionalmente associados, constituem importantes indicadores da condição mineral dos animais. Além dos resultados obtidos neste trabalho, outras pesquisas deverão ser conduzidas para conhecer as carências minerais da região semiárida e subsidiar a suplementação de energia, proteínas e minerais em animais criados em sistema extensivo. 


\section{CONCLUSÔES}

Teores séricos de Cu e Zn em caprinos e ovinos criados no sertão do estado de Pernambuco apresentam-se em situação marginal, sendo importante fator de risco para a ocorrência de deficiência, tanto inaparente quanto clínica, com as consequentes perdas econômicas, devendo-se, portanto, oferecer suplementação adequada destes nutrientes.

O período de seca é um importante fator sazonal que determina menor aporte sérico de Zn e hepático de Fe e Zn em caprinos e ovinos criados no sertão do estado de Pernambuco.

Considerando os teores de Fe e Mo encontrados, a deficiência de Cu na região estudada tem característica de deficiência marginal primária.

Agradecimentos.- Á Fundação de Amparo à Ciência e Tecnologia do Estado de Pernambuco (FACEPE) pela concessão da bolsa de mestrado; ao CNPq, pelo apoio ao projeto de pesquisa aprovado no edital Universal 2007 Faixa A (Edital MCT/CNPq 15/2007), e ao Programa de Sanidade em Caprinos e Ovinos no Estado de Pernambuco, coordenado pela Prof ${ }^{a}$. Dr ${ }^{a}$. Maria Cristina Oliveira Cardoso Coelho do DMV-UFRPE.

\section{REFERÊNCIAS}

Allen J.D. \& Gawthorne J.M. 1987. Involvement of the solid phase rumen digesta in the interactions between copper, molybdenum and sulphur in sheep. Brit. J. Nutr. 58:265-276.

Araújo Filho J.A., Sousa F.B. \& Carvalho F.C. 1996. Composição botânica e química da dieta de ovinos e caprinos em pastoreio combinado na região dos Inhamuns, Ceará. Revta Soc. Bras. Zootec. 25:383-395.

Antonelli A.C. 2007. Avaliação do uso de um sal mineral rico em molibdênio na prevenção da intoxicação cúprica acumulativa em ovinos. Tese de Doutorado, Faculdade de Medicina Veterinária e Zootecnia, Universidade de São Paulo, São Paulo, SP. 122p.

Blood D.C. 1994. Manual de Medicina Veterinária. Interamericana McGraw-Hill, Philadelphia. 790p.

Borges A.S., Amorim R.M., Kuchembuck M.R.G., Araújo R. S.2005. Correlação entre a atividade sérica da ceruloplasmina e os teores séricos e hepáticos de cobre em novilhas Nelore. Arq. Bras. Med. Vet. Zootec. 57(2):150-155.

Bondan E.F., Riet-Correa F. \& Giesta S.M. 1991. Níveis de cobre em fígados de bovinos no sul do Rio Grande do Sul. Pesq. Vet. Bras. 11(3/4):75-80.

Botha C.J., Geswan G.E. \& Minnaar P.P. 1995. Pharmacokinetics os ammonium tetrathiomolybdate following intravenous administration in sheep. Tydskr. South Afr. Vet. Assoc. 66(1):6-10.

Gonzales F.H.D., Julio B., Patinõ H.O. \& Ribeiro L.A. 2000. Perfil metabólico em ruminantes: seu uso em nutrição e doenças nutricionais. UFRGS, Porto Alegre. 31p.

Grace N.D. 1983. The mineral requirement of grazing ruminants. Glaxo New Zeland Ltd, Palmerston North. 150p.

Guedes K.M.R., Riet-Correa F., Dantas A.F., Simões S.V.D., Miranda Neto E.G., Nobre V.M.T. \& Medeiros R.M.T. 2007. Doenças do sistema nervoso central em caprinos e ovinos no semi-árido. Pesq. Vet. Bras. 27(1):29-38.

Humphries W.R. 1983. The influence of dietary iron and molybdenum on copper metabolism in calves. Brit. J. Nutr. 49:77-86.

Jones H.B., Gooneratner S.R. \& Howell J.McC. 1984. X-ray microanalysis of liver and kidney in copper loaded sheep with and without thiomolybdate administration. Res. Vet. Sci. 37:273-282.
Leite E.R., Araújo Filho J.A. \& Pinto F.C. 1995. Pastoreio combinado de caprinos com ovinos em caatinga raleada: desempenho da pastagem e dos animais. Pesq. Agropec. Bras. 30:1129-1134.

Marques A.P., Riet-Correa F., Soares M.P., Ortolani E.L. \& Giuliodori M.J. 2003. Mortes súbitas em bovinos associadas à carência de cobre. Pesq. Vet. Bras. 23(1):21-32.

McDowell L.R. 1999. Minerais para ruminantes sob pastejo em regiões tropicais, enfatizando $\circ$ Brasil. $3^{\text {rd }}$ ed. University of Florida, Gainesville. 292p.

Miles P.H., Wilkinson N.S. \& McDowell L.R. 2001. Analysis of Minerals for Animal Nutrition Research. $3^{\text {rd }}$ ed. USDA/T-STAR Grant, Florida. $117 \mathrm{p}$.

Mills C.F. 1987. Biochemical and physiological indicators of mineral status in animals: Copper, cobalt and zinc. J. Anim. Sci. 65:17021711.

Moraes S.S., Tokarnia C.H. \& Döbereiner J. 1998. Deficiências e desequilíbrios de microelementos em bovinos e ovinos em algumas regiões do Brasil. Pesq. Vet. Bras. 19(1):19-33.

Oregui L.M. \& Bravo M.V. 1993. El cobre, funciones y necesidades, p.9-22. In: Fernandez M.A.G. (Ed.), Patologia Relacionada con el Cobre: deficiencias e intoxicaciones. Luzans Ediciones, Madrid.

Ortolani E.L. 2002. Macro e microelementos, p.641-651. In: Spinosa H.S., Gorniak S.L. \& Bernadi M.M. (Eds), Farmacologia Aplicada à Medicina Veterinária. Guanabara Koogan, Rio de Janeiro.

Owen E.C. 1965. Pathological and biochemical studies of an outbreak of swayback in goats. J. Comp. Pathol.. 75:241-251.

Peixoto P.V., Malafaia P., Barbosa J.D. \& Tokarnia C.H. 2005. Princípios de suplementação mineral em ruminantes. Pesq. Vet. Bras. 25(3):195-200.

Pott E.B., Henry P.R., Zanetti M.A., Rao P.V., Hinderberger E.J. \& Ammerman C.B. 1999. Effetcs of hight molybdenum concentration and duration of feeding time on molybdenum and copper metabolism in sheep. Anim. Feed Sci. Technol. 79:93-105.

Riet-Correa F. 2004. Suplementação mineral em pequenos ruminantes no semi-árido. Ciênc. Vet. Trópicos 7(2/3):112-130.

Riet-Correa F. 2007. Deficiência de cobre, p.239-248. In: Riet-Correa, Schild A.L., Lemos R.A.A. \& Borges J.R. (Eds), Doenças de Ruminantes e Eqüinos. $3^{\mathrm{a}}$ ed. Pallotti, Santa Maria.

Sanz Lorenzo M.C., Casasnovas A.F. \& Verde Arribas M.T. 1996. La deficiencia de zinc, p.25-36. In: Fernandez M.A.G. (Ed.), Carencias Vitamínico-Minerales en el Ganado Ovino. Luzans Ediciones, Madrid.

Santos N.V.M., Sarkis J.E.S., Guerra J.L., Maiorka P.C., Hortelani M.A., Silva F.F. \& Ortolani E.L. 2006. Avaliação epidemiológica, clínica, anátomopatológica e etiológica de surto de ataxia em cabritos e cordeiros. Ciência Rural 36(4):1207-1213.

Senger C.C.D., Sanchez L.M.B., Pires M.B.G. \& Kaminski J. 1997. Teores minerais em pastagens do Rio Grande do Sul. II. Sódio, enxofre, zinco, cobre, ferro e manganês. Pesq. Agropec. Bras. 32(1): 101-108.

Silva L.A.F., Cunha P.H.J., Jardim E.A.G.V., Fiovaranti B.R.T., Silva M.A.M., Gonçalves J.R., Gonçalves P.P.C. \& Prazeres A. 2004. Efeito da administração parenteral de cobre sobre o ganho de peso, eritrograma e parênquimas, hepático e renal, em bovinos mestiços (Zebu x Europeu) confinados. Semina, Ciências Agrárias 25(3):225234.

Solaiman S.G., Maloney M.A., Qureshi M.A., Davi G. \& Andrea D. 2001. Effects of high copper supplements on performance, health, plasma copper and enzymes in goats. Small Rum. Res. 41:127-139.

Statistical Analyses System Institute 2000. SAS User's Guide: Statistics version. Cary, New York.

Suttle N.F. 1974. Recent studies of the copper-molybdenum antagonist. Proc. Nutr. Society 33:299-305.

Tebaldi F.L.H., Silva J.F.C., Vasquez H.M. \& Thiebaut J.T.L. 2000. 
Composição mineral das pastagens das regiões Norte e Noroeste do Estado do Rio de Janeiro. 2. Manganês, ferro, zinco, cobre, cobalto, molibdênio e chumbo. Revta Bras. Zootec. 29(2):616129.

Tokarnia C.H., Guimarães J.A., Canella C.F.C. \& Döbereiner J. 1971. Deficiências de cobre e cobalto em bovinos e ovinos em algumas regiões do Brasil. Pesq. Vet. Bras. 6:61-77.

Tokarnia C.H., Döbereiner J. \& Moraes S.S. 1988. Situação atual e perspectivas da investigação sobre nutrição mineral em bovinos no Brasil. Pesq. Vet. Bras. 8(1/2):1-16.

Tokarnia C.H., Döbereiner J., Moraes S.S. \& Peixoto P.V. 1999. Deficiências e desequilíbrios minerais em bovinos e ovinos: revisão dos estudos realizados no Brasil de 1987 a 1998. Pesq. Vet. Bras. 19(2): 47-62.
Tokarnia C.H., Döbereiner J. \& Peixoto P.V. 2000. Deficiências minerais em animais de fazenda, principalmente bovinos. Pesq. Vet. Bras. 20(3):127-138.

Tokarnia C.H., Peixoto P.V., Barbosa J.D., Brito M.F. \& Döbereiner J. 2010. Deficiências Minerais em Animais de Produção. Ed.Helianthus, Rio de Janeiro.

Underwood E.J. \& Suttle N.F. 1999. The Mineral Nutrition of Livestock. $3^{\text {rd }}$ ed. CAB International, New York. 614p.

Van Ryssen J.B.J. \& Stielau W.J. 1980. The effect of various levels of dietary copper and molybdenum on copper and molybdenum metabolism in sheep. South Afr. J. Anim. Sci. 10:37-47.

Van Ryssen J.B.J. \& Stielau W.J. 1981. Effect of different levels of dietary molybdenum on copper and Mo metabolism in sheep fed on high levels of Cu. Brit. J. Nutr. 45:203-210. 